\title{
Relationship of the 1979 Southern California Radon Anomaly to a Possible Regional Strain Event
}

\author{
M. H. Shapiro,' J. D. Melvin, T. A. Tombrello, and M. H. Mendenhall \\ W. K. Kellogg Radiation Laboratory, California Institute of Technology, Pasadena, California 91125 \\ P. B. LARSON \\ Geological and Planetary Sciences, California Institute of Technology, Pasadena, California 91125
}

\section{J. H. WHITCOMB}

CIRES, University of Colorado, Boulder, Colorado 80309

\begin{abstract}
During the second half of 1979 , anomalously high emanation of radon was recorded at two stations of the automated radon-thoron monitoring network operated by the W. K. Kellogg Radiation Laboratory of the California Institute of Technology. The two stations exhibiting major anomalies, Kresge and Dalton Canyon, are located approximately $30 \mathrm{~km}$ apart on the frontal fault system of the Transverse Ranges of southern California. At Kresge the anomaly began on June 21, 1979, and continued through December 1979. At Dalton Canyon the anomaly started about 3 weeks later and also continued through December 1979. At both sites the anomalous levels of radon decreased (but did not return entirely to normal values) shortly before October 15, 1979. During the week of October 15, 1979, a 6.6- $M$ earthquake occurred about $290 \mathrm{~km}$ to the southeast of the two stations, and later in that week, earthquakes of magnitude 4.2 and 4.1 occurred at Malibu and Lytle Creek. The latter two events were within $60 \mathrm{~km}$ of the monitors. A radon-thoron monitor at Lytle Creek recorded no long-term anomaly but did record a sharp spikelike decrease in the radon level on October 13, 1979. Coincident with our observations of anomalous radon levels, other investigators have reported anomalies or suspected anomalies in several other geodetic, geophysical, and geochemical signals from the same general region. The rapid temporal development of several of the anomalies together with the large area over which they were observed suggests that a large-scale strain event took place which may have been responsible both for the widespread anomalies and for the seismicity that occurred in the region subsequent to the onset of the anomalies.
\end{abstract}

\section{INTRODUCTION}

Since the 1965 Tashkent earthquake there have been a number of reports of radon anomalies preceding moderate or large earthquakes from the USSR [Sadovsky et al, 1972], China [Li et al., 1975], and Japan [Wakita et al., 1980]. Almost all of these reports have been based on the observation of changes in radon levels in groundwater. More recently, in the United States, several groups have been monitoring radon in soil gas [Mogro-Campero et al., 1980; King, 1980; Birchard and Libby, 1980] and in groundwater [Shapiro et al., 1980a; Talwani et al., 1980; Teng, 1980] in an attempt to observe precursory changes in radon levels. While several of the reported precursory radon anomalies have been recorded within a few tens of kilometers of the subsequent epicenter, there have been a number of reports of precursory radon anomalies at large distances from subsequent epicenters. For example, Teng [1980] tabulated data from the Kutzan station in China, where in a 4-year period, radon spikes of short duration were observed several days before eight earthquakes ranging in magnitude from 5.2 to 7.9. All of these earthquakes occurred on a Y-shaped fracture zone. The nearest event with a precursory anomaly was $54 \mathrm{~km}$ from the station, while the furthest occurred $345 \mathrm{~km}$ from the station. During the same period one radon spike was observed with no subsequent earthquake, and for one $6.5-M$ earthquake $420 \mathrm{~km}$ distant on

\footnotetext{
${ }^{1}$ Also affiliated with the Physics Department, California State University, Fullerton, California 92634.

Copyright 오 1981 by the American Geophysical Union.
}

the same fracture zone no precursory anomaly was observed.

Such reports of supposedly precursory radon anomalies at great distance from subsequent earthquakes often have been received with considerable skepticism, particularly in the United States, since the half-life of a radon atom is too short (3.8 days) to permit its movement more than several tens of meters from its point of production even if active subsurface transport mechanisms are invoked [Tanner, 1978]. In addition, during the short history of the radon monitoring effort in the United States there have been only a few previous reports of precursory radon anomalies, and generally, these have been associated with nearby earthquakes. In this paper we report the observation of a radon anomaly which coincided with several other geophysical and geochemical anomalies and which appears to have been associated with an earthquake some $\mathbf{2 9 0}$ $\mathrm{km}$ from the site of the radon anomalies. These observations are discussed with reference to two recently proposed models which would account for much of the anomalous data observed in southern California during 1979.

\section{EXPERIMENTAL Procedure}

A full description of the automated radon-thoron monitors used in the California Institute of Technology radon monitoring program has been given by Melvin et al. [1978]. Radon data from the Kresge site, which is located in the San Rafael Hills of Pasadena $\left(34.089^{\circ} \mathrm{N}, 118.103^{\circ} \mathrm{W}\right.$ ), have been obtained from two monitors. The first prototype unit monitored radon and thoron from a 24.1-m-deep static borehole in granite from April 1977 to March 1979. Data from this period of operation 
have been discussed by Shapiro et al. [1980a]. A few apparently precursory changes in the radon level were observed before some local earthquakes. The largest of these was a 5.0-M event which occurred on January 1, 1979, off the coast at Malibu about $54 \mathrm{~km}$ west of the monitor. For about 45 days prior to the earthquake a series of positive spikes were observed in the radon data [Shapiro et al., 1980a]. The prototype monitor was replaced in April 1979 with a more advanced unit which incorporated dial-up telemetry. The new unit was coupled to the same borehole as the prototype, and within a few days after start-up the radon levels observed with the new monitor were essentially the same as those observed from the prototype shortly before the changeover.

Monitors of the new type began operation over static boreholes of similar depth at Dalton Canyon $\left(34.102^{\circ} \mathrm{N}\right.$, $\left.117.486^{\circ} \mathrm{W}\right)$ and Lytle Creek $\left(34.140^{\circ} \mathrm{N}, 117.287^{\circ} \mathrm{W}\right)$ in April 1979 and March 1979, respectively. At all three sites the boreholes are cased through the overburden, and the monitor vaults are coupled directly to the casing to reduce atmospheric environmental effects. The Kresge and Dalton Canyon boreholes are both located in small, steep canyons where the rock which is penetrated is heavily fractured. At Kresge the rock is granite, while at Dalton Canyon it is granodiorite. At Lytle Creek the borehole is located on a terrace near an outcropping of weathered granite. The overburden is relatively thin at Kresge and Dalton Canyon (less than $5 \mathrm{~m}$ ), while at Lytle Creek it is about $13 \mathrm{~m}$ deep at the borehole location. The monitors strip radon from the boreholes every 8 hours. The on-board microcomputer stores-in addition to radon and thoron data - a background count, instrument temperature and ambient temperature, and a number of engineering parameters. The background count serves as a sensitive check on instrument stability. The temperature data are used to correct radon data for instrument wall effects, as described by Melvin et al. [1978]. The temperature corrections are applied to 24-hour and 72-hour running averages of the data; however, the difference between raw radon data and temperaturecorrected data is not significant when large-scale features of the data are examined.

\section{RADON OBSERVATIONS}

Complete sets of radon data (without temperature corrections) from the Kresge, Dalton Canyon, and Lytle Creek stations from the inception of monitoring at each site are shown in Figure 1. The Kresge data set is considerably longer than the other two and provides a baseline against which the anomalous data recorded during the latter half of 1979 can be compared. During the first 2 years of operation the data from Kresge exhibited a weak annual cycle that is believed to be the result of thermoelastic strains and hydrological effects [Shapiro et al., 1980a]. Heavy winter rainfall has been observed to cause increases of short duration in the radon levels at several of our monitoring sites [Shapiro et al, 1980b]. The winter of 1979-1980 was characterized by a series of four unusually heavy rainstorms, and the large peaks that are seen in the radon data from Kresge and Lytle Creek during January and February of 1980 are responses to rapid recharge. The fluctuations in the Kresge radon level during the first 3 months of 1978 also were associated with heavy winter rainfall. During the first 2 years of monitoring at Kresge the radon levels during the late summer and fall months generally were free of large fluctuations and during the late summer months were near a minimum.

The radon data sets from Dalton Canyon and Lytle Creek are not as extensive as the Kresge data set. As a result it is not possible to determine the 'baseline' levels for these sites with as much confidence. However, it appears that the data from the Lytle Creek site exhibit an annual cycle that is driven predominantly by hydrological factors, namely, the annual recharge and draining of the alluvial overburden on the terrace and in a nearby side canyon. The data from the Dalton Canyon site do not show as obvious an annual cycle as those recorded at Kresge and Lytle Creek.

The most striking feature of the data shown in Figure 1 is the large increase in the radon level at Kresge which began in late June of 1979 and persisted throughout the remainder of the year. The data obtained during this period from the Kresge, Dalton Canyon, and Lytle Creek stations is replotted with an expanded time scale in Figure 2. Large radon spikes started to appear in the Kresge data beginning about June 21, 1979 , and within 2 weeks the average levels of radon being measured at Kresge exceeded any that had been measured at this site during the previous 2 years. The character of the radon signal also was considerably different from that of the previous data. In addition to the general increase in the radon level, large and rapid fluctuations occurred, lasting from less than 1 day to a few days. Several checks were carried out to ensure that the monitor was operating properly. The background count (taken before each run) and the thoron levels were found to be within normal limits, and none of the engineering data were abnormal.

About 3 weeks after the data became anomalous at Kresge, large radon spikes also were observed in the data from the Dalton monitor. While baseline data from previous years did not exist at the Dalton site, the data trend at Dalton had been reasonably smooth from the start of monitoring through early July except for a short time in early June that immediately followed a period when the monitor vault had been opened for service. Therefore the radon spikes at Dalton were considered anomalous.

During the same period the data from the Lytle Creek monitor were free of the large fluctuations seen at Kresge and Dalton. However, $1 \frac{1}{2}$ days before the Imperial Valley earthquake there was one run with substantially lower than normal radon. Inspection of the engineering data from that run indicated that the air pump of the monitor did not operate for its usual full 8-min cycle. This behavior has been observed occasionally as a symptom of incipient battery failure. In the case of battery failure this condition becomes progressively worse. However, in this instance, normal pump operation took place for several runs before and after the one with low radon. A routine maintenance check 6 weeks after the low run revealed that the electromechanical system battery, which is operated in a float charged configuration, was operating with a dead cell. In this condition the battery still had sufficient capacity to operate the mointor air pump for a full $8 \mathrm{~min}$. We now speculate that the increased back pressure on the air pump from a temporary increase in water level could have accounted for a short air pump cycle and thus one run with low radon count. Our experience with the field monitors has indicated that an 8-min air pump cycle is more than sufficient to fully strip radon from the borehole. Thus the low radon reading probably did not result from incomplete stripping. The thoron count 


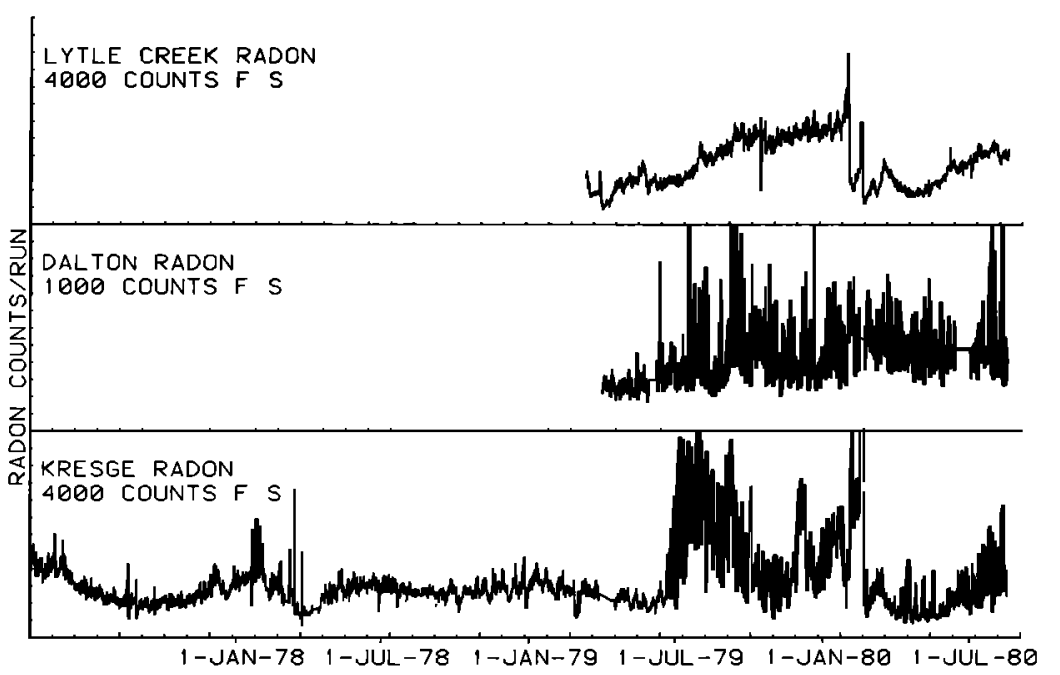

Fig. 1. Radon levels recorded at Kresge, Dalton Canyon, and Lytle Creek stations from the inception of monitoring at each site. The full scale count (relative units) for each time series is noted in the figure. Missing data have been patched with smooth line segments.

from the run in question was normal, which would further support this interpretation.

\section{OTHER ANOMALIES}

During the same time period in which the large radon anomalies at Kresge and Dalton Canyon were observed, there also were several other anomalies reported in southern California. Savage et al. [1981] report the results of laser geodimeter strain measurements near Palmdale that were repeated frequently during the period from 1971 to 1980 . These measurements indicate that in addition to a uniform right-lateral shear strain ( $0.35 \mu \mathrm{rad} / \mathrm{yr}$ engineering shear) across the San Andreas fault, a 1-microstrain contraction perpendicular to the fault accumulated gradually during 1974-1978. Several measurements taken during 1979 indicate that essentially all of this contraction was released without local seismicity between February and November 1979 and then about half the contraction was recovered between November 1979 and March 1980.

In addition to the laser geodimeter work of Savage et al. [1981] the Aries very long baseline radio interferometry program [Resch, 1979] has provided independent geodetic data from southern California since August 1974. Repeated measurements of the baseline between Goldstone and Pasadena (Jet Propulsion Laboratory) during that time period appear to show two episodes of rapid strain which are interpreted as sudden plate motion during 1975 and 1978-1979 [Whitcomb, 1980]. Temporal changes in deformation during $1978-1980$ as deduced from the Aries data are in good agreement with the results of Savage et al. [Niell, 1979; P. MacDoran, private

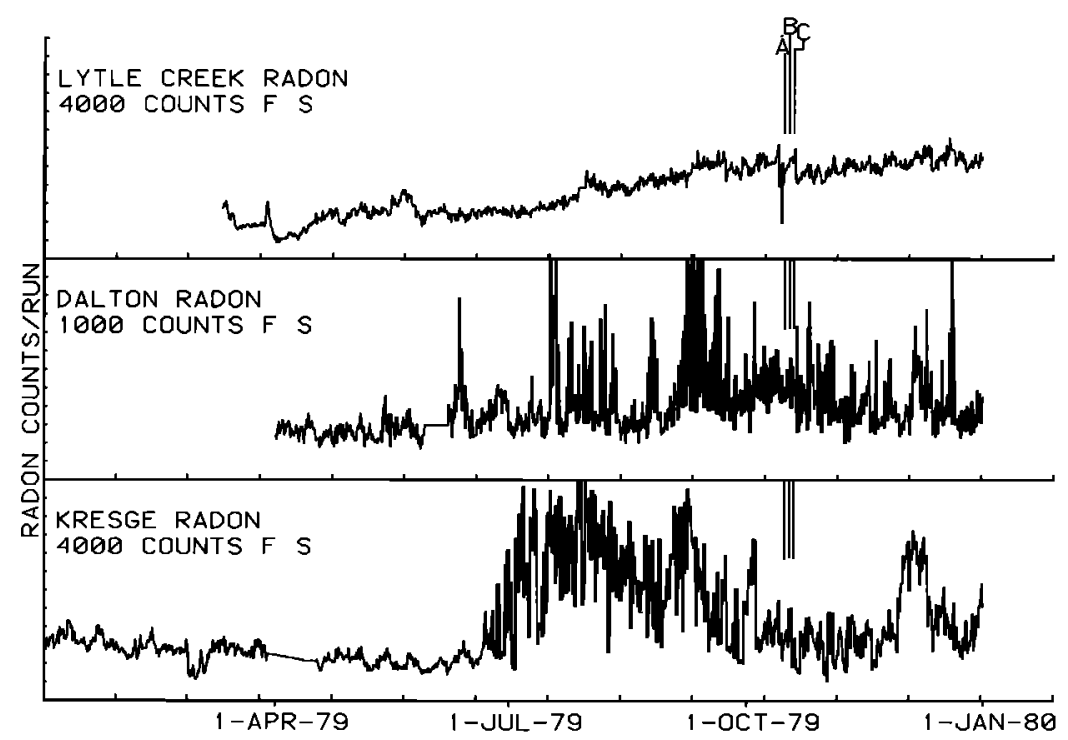

Fig. 2. Radon levels recorded at Kresge, Dalton Canyon, and Lytle Creek stations during 1979. The times at which the Imperial Valley (6.6 M), Malibu (4.2 M), and Lytle Creek (4.1 M) earthquakes occurred are denoted by $A, B$, and $C$, respectively. The full scale count (relative units) for each time series is noted in the figure. Missing data have been patched with smooth line segments. 
communication, 1980]. For both the laser geodimeter data and the Aries data the period of most rapid strain change in southern California coincides quite closely with the period during which the large radon anomaly was observed.

During the same period, Whitcomb [1979] reported a decrease in gravity for the Pasadena area and Lytle Creek relative to Goldstone of $50 \mu \mathrm{Gal}$, and the same change in absolute gravity was confirmed during this period at Lytle Creek [Goodkind, 1980]. In addition, Lienert et al. [1980] report a relatively large shift in the direction of the apparent electrical resistivity tensor in the region just to the north of the 'big bend' in the San Andreas fault, and Williams and McWhirter [1979] reported changes in magnetic field measurements extending over a substantial part of the transverse ranges during 1979.

That part of the frontal fault system of the Transverse Ranges on which the Kresge and Dalton Canyon stations are located has been relatively quiet seismically from the inception of instrumental monitoring in 1932 until 1970. A general increase in the seismicity in this region has been noted in the past decade; however, there were no particularly unusual changes in seismicity along the frontal faults during the period of the anomaly (L. K. Hutton, private communication, 1980). However, during the past 2 years there has been a general increase in the seismicity of southern California [Whitcomb, 1980]. Prior to the start of the radon anomaly all of the earthquakes of $M_{L}=5.0$ or greater that were part of this increase had been in the Transverse Ranges. The most obvious anomaly in the seismicity of southern California during the period of the radon anomaly was the sharp reduction in Imperial Valley seismicity prior to the 6.6-M Imperial Valley event. There was a $40 \%$ reduction in the number of earthquakes in the Imperial Valley during the 15-week period preceding the Imperial Valley earthquake [Johnson and Hutton, 1980]. This coincides quite closely with the period of increased radon at the Kresge and Dalton sites.

In addition to these geodetic and geophysical anomalies, Craig et al. [1980] reported significant anomalies in the radon and helium levels at Arrowhead Hot Springs. This site is located about $20 \mathrm{~km}$ to the east of our Lytle Creek station and is near the San Andreas fault zone north of San Bernardino (see Figure 3). This spring had been sampled at approximately monthly intervals since 1975 . While these grab sample data do not have the time resolution of our near-real-time radon data, the temporal development of the anomalies at Arrowhead Hot Springs was quite similar to the Kresge data with the exception that the increase began about a month earlier. Craig et al. [1980] attribute the Arrowhead Hot Springs anomalies to an earthquake swarm at Big Bear Lake which occurred in June and July of $1979\left(M_{L}=4.8\right)$ some $32 \mathrm{~km}$ east of the site; however, the 6-month duration of the anomalies extends well past the time of the Big Bear swarm, which would suggest that they were related to the other southern California anomalies.

It should be noted that during this period of widespread anomalies in southern California, data from several other radon monitoring sites in the same region did not exhibit significant anomalies.

\section{Discussion}

The geodetic, geophysical, and geochemical anomalies observed in southern California during 1979 are striking because of their variety, the size of the area over which they occurred, and their correlation in time. Of particular interest is the rapidity with which the anomalies developed. The availability of the near-real-time radon data provided an important impetus for increasing the frequency of the laser geodimeter and very long baseline interferometry surveys so that the rapid geodetic changes could be observed with reasonable time resolution.

At this point the interpretation of the anomalies is not completely clear. The major geodetic and geochemical anomalies and the geophysical anomalies, with the exception of seismicity, appear to have been limited to the vicinity of the Transverse Ranges, while the major anomaly in the seismicity of southern California occurred more than $200 \mathrm{~km}$ to the southeast in the Imperial Valley. The seismicity anomaly indeed was followed by a relatively large earthquake, and the correspondence in the temporal development of the seismicity anomaly with the anomalies which occurred in the Transverse Ranges suggests a possible connection between the Imperial Valley earthquake and all of the southern California anomalies.

During the week following the Imperial Valley earthquake, two smaller seismic events occurred in the Transverse Ranges. However, it seems unlikely that these events (4.2 M near Malibu and 4.1 $M$ near Lytle Creek) would be preceded by anomalies of such an extensive nature. However, it is possible that the sharp radon decrease observed at the Lytle Creek station was associated in a purely local sense with the 4.1- $M$ Lytle Creek event, since the epicenter for this event was only $5 \mathrm{~km}$ from the monitor.

Because of the wide area covered by the anomalies and the variety of parameters which exhibited anomalies, it seems unlikely that nontectonic environmental factors were responsible. Rather, the data suggest that some type of regional strain event was occurring in southern California during this period. Two quite different models have been proposed to explain the anomalies. Savage et al. [1981] employ a dislocation model in an attempt to explain their geodetic data. On their model the upper part of the crust slips over a horizontal plane of detachment. The line of dislocation is presumed to be moving from the northeast to the southwest (or the reverse) across the strike of the San Andreas fault in the big bend area. An interesting feature of the model is the prediction of a relatively rapid compressional phase following the dilatation observed during 1979. The model is essentially local and would not directly explain the Imperial Valley seismicity.

Whitcomb [1980] has suggested that episodes of rapid plate motion occur along the boundary of the Pacific and North American plates. These episodes are expected to be marked by a general increase in seismicity throughout California. He also suggests that in the region of the big bend of the San Andreas fault a substantial amount of crustal shortening is required to accommodate the plate motion. This, in turn, leads to creep at depth on the thrust fault systems in the Transverse Ranges. As evidence for this view, Whitcomb [1980] cites the coincidence of periods of high seismicity in California during 1975 and 1979-1980 with Aries data which indicate accelerated plate motion and crustal shortening. Whitcomb's picture qualitatively explains both the Imperial Valley seismicity and the major anomalies in the Transverse Ranges as separate manifestations of the same event.

While the existing data appear to be insufficient to validate either model, it does appear that they have delineated a strain event that developed quite rapidly in time. The observation of a number of such events in the future should provide the data necessary to refine models of crustal behavior for southern 


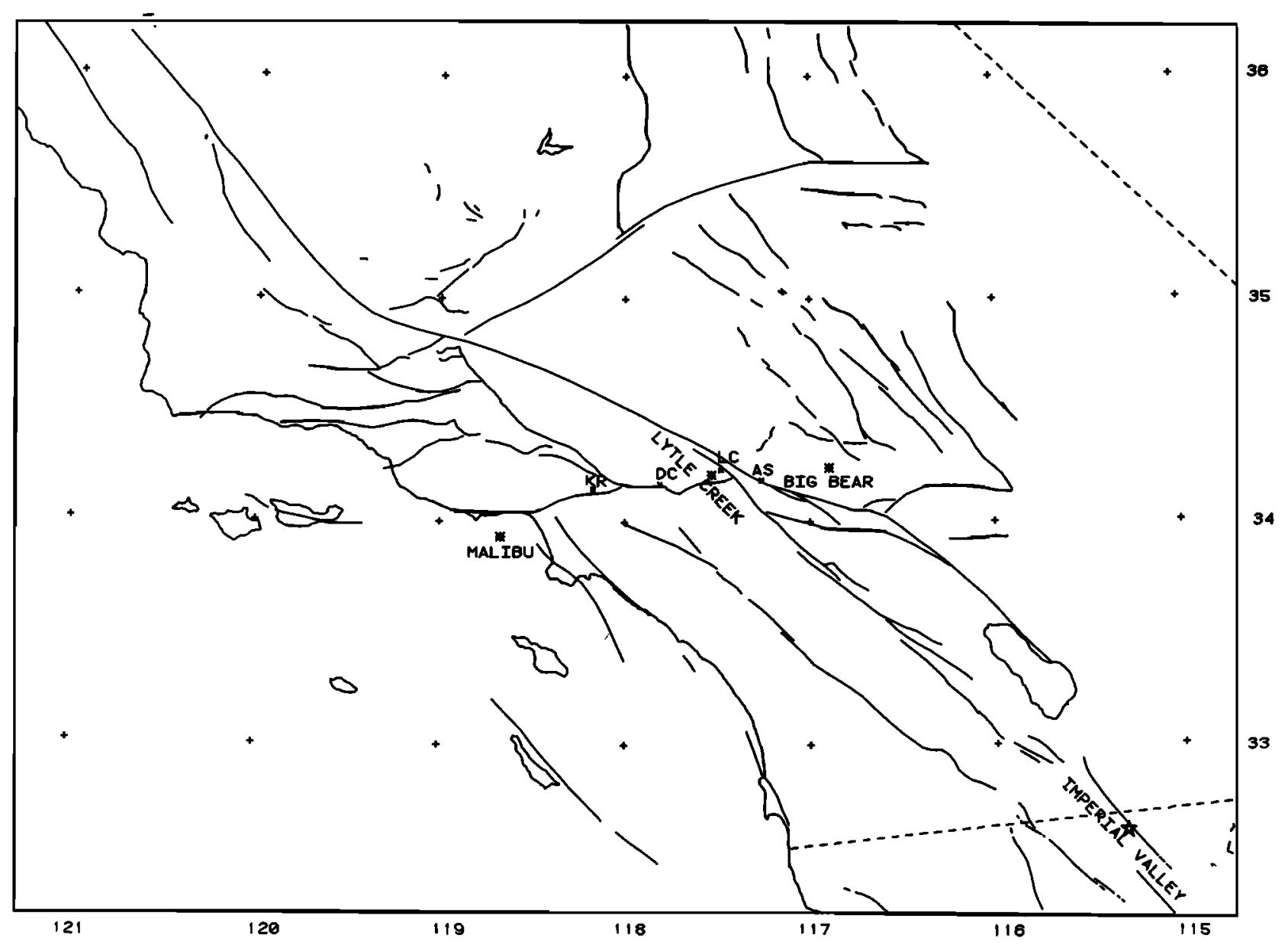

Fig. 3. Index map showing relevant tectonic features of southern California and locations of radon monitoring stations and earthquake epicenters. The California Institute of Technology stations at Kresge, Dalton Canyon, and Lytle Creek are denoted by KR, DC, and LC, respectively. The radon monitoring site operated by Craig at Arrowhead Hot Springs is denoted by AS. The epicenters of the Big Bear, Imperial Valley, Malibu, and Lytle Creek earthquakes also are indicated.

California. To this end it is essential that regular monitoring of geodetic, geophysical, and geochemical parameters continue in the region. Where possible, the monitoring should be on a real-time or near-real-time basis.

The observation of anomalies at a number of sites scattered throughout the Transverse Ranges but not at all sites in the region suggests that only certain types of sites are sensitive to regional strain. This is similar to the Chinese experience [Jiang and $L i, 1980 a, b$ ] and would imply that the detailed characterization of monitoring sites is a very necessary factor in an earthquake prediction program.

Acknowledgments. This work was supported in part by USGS contract 14-08-0001-17734 and NSF grant PHY79-23638 at the California Institute of Technology. We thank H. Craig, C. Johnson, L. K. Hutton, and J. Savage for providing data prior to publication. We also thank L. K. Hutton and T. Heaton for helpful comments on this paper.

\section{REFERENCES}

Birchard, G. F., and W. F. Libby, Soil rador conczntration changes preceding and following four magnitude 4.2-4.7 earthquakes on the San Jacinto fault in southern California, J. Geophys. Res., 85, 3100, 1980.

Craig, H., Y. Chung, J. E. Lupton, S. Damasceno, and R. Poreda, Investigation of radon and helium as possible fluid phase precursors to earthquakes, Rep. SIO 80-8, Scripps Inst. of Oceanogr., La Jolla, Calif., 1980.
Goodkind, J. M., Continuous gravity measurements in the region of the Palmdale uplift, Geol. Surv. Open File Rep. U.S., 80-842, 362, 1980.

Jiang, F., and G. Li, The application of geochemical methods in earthquake prediction in China, report, W. K. Kellogg Radiat. Lab., Calif. Inst. of Technol., Pasadena, 1980a.

Jiang, F., and G. Li, Experimental studies on the mechanisms of seismo-geochemical precursors, report, W. K. Kellogg Radiat. Lab., Calif. Inst. of Technol., Pasadena, $1980 \mathrm{~b}$.

Johnson, C. E., and L. K. Hutton, The 15 October, 1979 Imperial Valley earthquake: A study of aftershocks and prior seismicity, Geol. Surv. Prof. Pap. U.S., in press, 1980.

King, C. Y., Episodic radon changes in subsurface soil gas along active faults and possible relation to earthquakes, $J$. Geophys. Res., 85 , $3065,1980$.

Li, L. P., W. D. Kun, and W. T. Min, Studies on forecasting earthquakes in light of abnormal variation of $R_{n}$ concentration in ground water, Acta Geophys. Sin., 18, 279, 1975.

Lienert, B. R., J. H. Whitcomb, R. J. Phillips, I. K. Reddy, and R. A. Taylor, Long term variations in magnetotelluric apparent resistivities near the San Andreas fault in southern California, J. Geomagn. Geoelectr., in press, 1980.

Melvin, J. D., M. H. Shapiro, and N. A. Copping, An automated radon-thoron monitor for earthquake prediction research, Nucl. Instrum. Methods, 153, 239, 1978.

Mogro-Campero, A., R. L. Fleischer, and R. S. Likes, Changes in subsurface radon concentrations associated with earthquakes, $J$. Geophys. Res., 85, 3053, 1980.

Niell, A. E., Further monitoring of the Pasadena, Goldstone, Owens Valley baselines by VLBI geodesy (abstract), Eos Trans. AGU, 60 , 810, 1979. 
Resch, G. M., Aries/satellite laser ranging comparisons: Progress and plans (abstract), Eos Trans. AGU, 60, 810, 1979.

Sadovsky, M. A., I. L. Nersesov, S. K. Nigmatullaev, L. A. Latynina, A. A. Lukk, A. N. Semenov, I. G. Simbereva, and V. I. Ulomov, The processes preceding strong earthquakes in some regions of middle Asia, Tectonophysics, 14, 295, 1972.

Savage, J. C., W. H. Prescott, M. Lisowski, and N. E. King, Strain on the San Andreas fault: Rapid aseismic change near Palmdale, California, Science, $211,56,1981$.

Shapiro, M. H., J. D. Melvin, T. A. Tombrello, and J. H. Whitcomb, Automated radon monitoring at a hard-rock site in the southern California Transverse Ranges, J. Geophys. Res., 85, 3058, $1980 a$.

Shapiro, M. H., J. D. Melvin, T. A. Tombrello, P. B. Larson, J. H. Whitcomb, Rainfall induced changes in subsurface radon levels (abstract), Eos Trans. AGU, 61, 573, 1980 b.

Talwani, P., W. S. Moore, and J. Chiang, Radon anomalies and microearthquakes at Lake Jocassee, South Carolina, J. Geophys. Res., $85,3079,1980$.
Tanner, A. B., Radon migration in the ground: A supplemental review, Geol. Surv. Open File Rep. U.S., 78-1050, 1978.

Teng, $T$., Some recent studies on groundwater radon content as an earthquake precursor, J. Geophys. Res., 85, 3089, 1980.

Wakita, H., Y. Nakamura, M. Noguchi, and T. Asada, Radon anomaly-Possible precursor of the 1978 Izu-Oshima-Kinkai earthquake, Science, 207(4433), 882, 1980.

Whitcomb, J. H., Recent temporal gravity changes in southern California (abstract), Eos Trans. AGU, 60, 810, 1979.

Whitcomb, J. H., Regional crustal distortion events in southern California: A confirmation of jerky plate motion?, report, CIRES, Univ. of Colo., Boulder, 1980.

Williams, F. J., and J. L. McWhirter, Magnetic field monitoring of tectonic stress, southern California (abstract), Eos Trans. AGU, 60, 948, 1979.

(Received August 29, 1980;

revised October 24, 1980;

accepted October 28, 1980.) 